\title{
In vitro-analysis of kinematics and intradiscal pressures in cervical arthroplasty versus fusion - A biomechanical study in a sheep model with two semi-constrained prosthesis
}

\author{
Dorothea Daentzer ${ }^{1 *}$, Bastian Welke ${ }^{2}$, Christof Hurschler ${ }^{2}$, Nathalie Husmann $^{3}$, Christina Jansen $^{4}$, \\ Christian Heinrich Flamme ${ }^{5}$ and Berna Ida Richter ${ }^{2,6}$
}

\author{
* Correspondence: \\ dorothea.daentzer@ddh-gruppe.de \\ 'Orthopedic Department, Hannover \\ Medical School, Diakoniekrankenhaus \\ Annastift gGmbH, Anna-von-Borries-Str. \\ 1-7, 30625 Hannover, Germany \\ Full list of author information is \\ available at the end of the article
}

\begin{abstract}
Background: As an alternative technique to arthrodesis of the cervical spine, total disc replacement (TDR) has increasingly been used with the aim of restoration of the physiological function of the treated and adjacent motions segments. The purpose of this experimental study was to analyze the kinematics of the target level as well as of the adjacent segments, and to measure the pressures in the proximal and distal disc after arthrodesis as well as after arthroplasty with two different semi-constrained types of prosthesis.

Methods: Twelve cadaveric ovine cervical spines underwent polysegmental (C2-5) multidirectional flexibility testing with a sensor-guided industrial serial robot. Additionally, pressures were recorded in the proximal and distal disc. The following three conditions were tested: (1) intact specimen, (2) single-level arthrodesis C3/4, (3) single-level TDR C3/4 using the Discover ${ }^{\circledast}$ in the first six specimens and the activ ${ }^{\circledR} \mathrm{C}$ in the other six cadavers. Statistical analysis was performed for the total range of motion $(\mathrm{ROM})$, the intervertebral $\mathrm{ROM}$ (iROM) and the intradiscal pressures (IDP) to compare both the three different conditions as well as the two disc prosthesis among each other.

Results: The relative iROM in the target level was always lowered after fusion in the three directions of motion. In almost all cases, the relative iROM of the adjacent segments was almost always higher compared to the physiologic condition. After arthroplasty, we found increased relative IROM in the treated level in comparison to intact state in almost all cases, with relative $\mathrm{iROM}$ in the adjacent segments observed to be lower in almost all situations. The IDP in both adjacent discs always increased in flexion and extension after arthrodesis. In all but five cases, the IDP in each of the adjacent level was decreased below the values of the intact specimens after TDR. Overall, in none of the analyzed parameters were statistically significantly differences between both types of prostheses investigated.

Conclusion: The results of this biomechanical study indicate that single-level implantation of semi-constrained TDR lead to a certain hypermobility in the treated segments with lowering the ROM in the adjacent levels in almost all situations.

Keywords: Total disc replacement, Cervical spine, Adjacent level biomechanics, Intradiscal pressure, Cervical arthroplasty, Disc prosthesis, Fusion, Arthrodesis, Range of motion, Sheep model
\end{abstract}




\section{Background}

Cervical disc arthroplasty has become an alternative technique to intervertebral fusion. One reason for this trend is the observation that in clinical studies, patients with a history of cervical arthrodesis seem to have a higher incidence of adjacent segment degeneration [1-3]. Furthermore, in biomechanical investigations, most authors have reported an increase in the segmental range of motion (ROM) and the intradiscal pressure (IDP) in the levels proximal and distal to a simulated mono- or bisegmental arthrodesis [4-13]. In contrast, with arthroplasty, the kinematics in the target segment as well as in the neighboring segments reach near to physiologic state, indicating an almost physiologic restoration of the affected motion segments $[4,6-8,14,15]$.

For in vitro-testing, cadaveric specimens from the human spine are often used as a biomechanical model. However, factors limiting the interpretation of results include confounding effects due to variability in age, height, gender, stiffness, bone quality, as well as the grade of degenerative changes inherent in cadaver specimens. In contrast, spinal specimens from some animals are generally easier to obtain and more homogeneous than human cadaver specimens. For this reason, several authors have performed comparative biomechanical investigations with the aim of identifying adequate substitute animal models for the human spine. The ovine cervical spine has for instance been suggested as an accepted substitute for in vitro-testing [16-18].

The primary objective of the present study was to quantify changes in operative- and adjacent-level kinematics like total ROM (tROM) and intervertebral ROM (iROM) and the IDP after monosegmental arthroplasty in comparison with those in the intact condition and after a single-level arthrodesis. The secondary objective was to compare the results between two different types of semi-constrained disc prosthesis using the same test set-up. As the goal of both implants is to restore the physiologic function of the motion segment and its kinematics, the purpose of this study was to show, whether these criteria can be fulfilled.

\section{Methods}

\section{Specimen preparation}

Twelve fresh frozen cadaveric cervical spines from full-grown sheep with a minimum age of two years were used in this investigation. Before biomechanical analysis, dual-energy $\mathrm{x}$-ray absorptiometry (DXA) was performed to exclude any specimens with pathologically low bone mineral density ( $t$-score more than -2.5 ). In preparation for biomechanical testing, the cervical spines were thawed to room temperature and dissected clear of all residual musculature. Care was taken to preserve all ligamentous structures and their attachments, as well as the intervertebral discs and facet joint capsules. Three motion segments, from $\mathrm{C} 2$ through $\mathrm{C} 5$, were tested in a polysegmental setup. The proximal (C2) and distal (C5) ends of the specimen were embedded in cold curing methylmethacrylate resin (Technovit, Heraeus Kulzer GmbH, Wehrheim, Germany) using three perpendicular screws per endplate for additional stabilization. Markers for the optical tracking system were inserted in the vertebral bodies of $\mathrm{C} 2, \mathrm{C} 3$ and $\mathrm{C} 4$ by connecting rods. Pressure sensors were placed in the centers of the discs $\mathrm{C} 2 / 3$ and $\mathrm{C} 4 / 5$ under fluoroscopic control.

\section{Three-dimensional motion segment testing}

Testing was performed using a sensor-guided six axis industrial robot (KUKA GmbH, Augsburg, Germany) which is a validated method against the Pure Moment Apparatus 
(PMA) and capable of applying pure, unconstrained rotational moments about three axes $(x, y, z)[19,20]$. Hereby, nondestructive pure-moment loading modes were applied: flexion and extension ( $x$-axis, $\pm 2.0 \mathrm{Nm}$ ), lateral bending ( $z$-axis, $\pm 2.0 \mathrm{Nm}$ ), and axial rotation $(y$-axis, $\pm 2.0 \mathrm{Nm})$. Loading was applied to the superior end (C2) of the vertically oriented specimen, whereas the distal portion of the cadaver (C5) remained fixed to the socket of the robot. No axial preload was used. Each test was repeated for three loading and unloading cycles at a rate of 0.2 degrees/second which approaches quasistatic testing conditions. The data from the third cycle were used for computational analysis. The tROM of the polysegment C2-5 was measured by the robot itself. To prevent desiccation during assessment, specimens were moistened with $0.9 \% \mathrm{NaCl}$ sterile irrigation solution.

\section{Segmental ROM}

For evaluating the iROM in the segments $\mathrm{C} 2 / 3, \mathrm{C} 3 / 4$ and $\mathrm{C} 4 / 5$, an optical tracking system (Polaris Northern Digital Incorporation, Ontario, Canada) was used. A rigid rod connected the tool with its four optical markers to each vertebral body of $\mathrm{C} 2, \mathrm{C} 3$ and C4. One tool was fixed to the socket of the robot, to which the most distal vertebral body (C5) was attached (Figure 1).

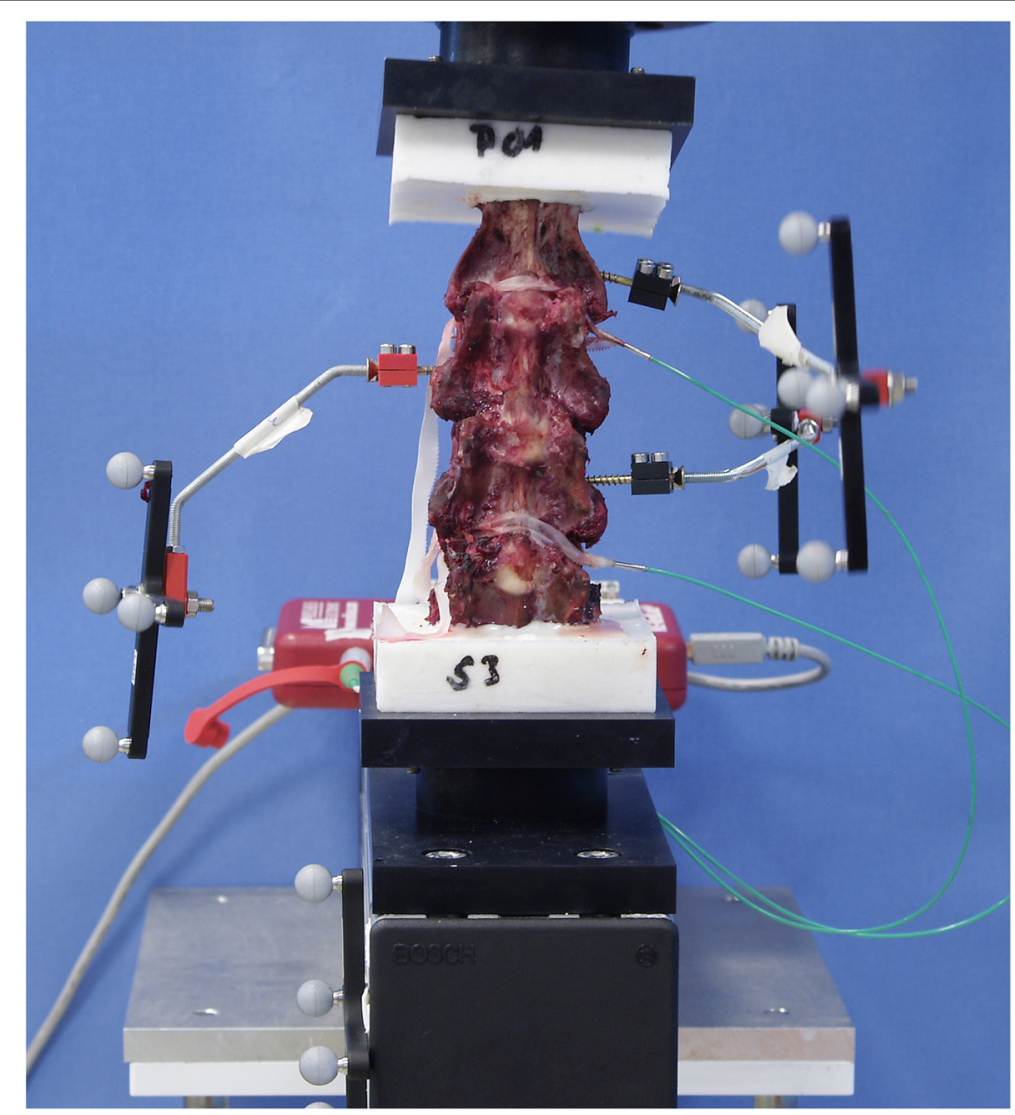

Figure 1 Anterior view of an intact spine specimen. Each rigid rod connected four optical markers to the vertebral bodies of C2 (left side), C3 (right side) and C4 (left side) for the optical tracking system, whereas the most distal tool was fixed to the socket of the robot, simulating the vertebral body of $\mathrm{C} 5$. The intradiscal pressure measuring sensors were inserted into the discs C2/3 and C4/5 from the left side and loosely fixed by elastic tapes to prevent dislocation. 


\section{Intradiscal pressures}

Specially manufactured piezoelectric pressure measuring sensors (FMSPEZ07, MIPM $\mathrm{GmbH}$, Mammendorf, Germany) were inserted into the discs of C2/3 and C4/5 from the left side (Figure 1). Their central location in the nucleus pulposus was controlled under fluoroscopy in anterior-posterior (a.p.) and lateral view. The pressure data were recorded under continuous visual control on a display. The maximum (saturation) pressure of the sensors was 7 bar.

\section{Reconstructive conditions}

The specimens were divided into two groups (group 1: specimen 01 to 06; group 2: specimen 07 to 12 ) and investigated in three conditions: intact, fused at the C3/4 level, and with two different types of arthroplasty, respectively as follows. After the first analysis of the intact polysegment C2-5 (group 1 and 2), a complete discectomy was performed at the level C3/4 in each specimen. The posterior longitudinal ligament (PLL) was preserved because of its pivotal role in stability [21]. Then a tricortical bone graft, which had been taken from a spinous process of the lower cervical spine, was inserted in the disc space and an anterior plate (ABC2 Anterior Cervical Plating System, Aesculap AG \& Co. KG, Tuttlingen, Germany) was supplemented to simulate a single-level fusion (group 1 and 2) (Figure 2a). After testing this situation in all specimens of both groups, the plate, the screws and the bone graft were removed. Thereafter, the corresponding endplates were prepared using a high-speed burr to ensure adequate implant positioning. Cervical arthroplasty was performed according to the recommendations of the implant manufacturer. In the first six specimens (group 1), the Discover ${ }^{\oplus}$-prosthesis ("TDR Type D”) (DePuySpine GmbH, Kirkel-Limbach, Germany) was inserted at the C3/4 level (Figure 2b), in the other six cadavers (group 2), the activ ${ }^{\bullet} \mathrm{C}$ ("TDR Type A") (Aesculap AG \& Co. KG, Tuttlingen, Germany) was utilized as TDR, also at the C3/4 level (Figure 2c).

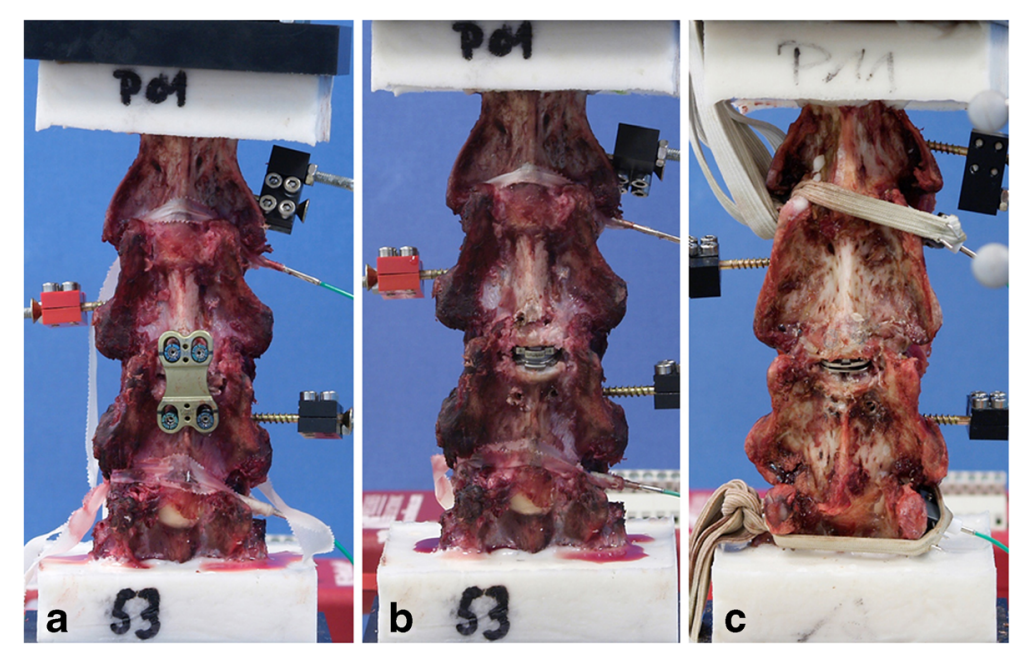

Figure 2 Anterior view of the specimens in the different conditions (C2-C5): a Single-level arthrodesis C3/4 with ABC2-Plate, b single-level TDR C3/4 with Type D-prosthesis, and c single-level TDR C3/4 with Type A-prosthesis. 


\section{Radiographic control}

All implanted disc prosthesis had a.p. and lateral radiographs to check their correct position in the intervertebral space (Figure 3).

\section{Data and statistical analysis}

For statistical analysis, the data (mean value and standard deviation $=\mathrm{SD}$ ) from the third loading cycle for the six main spinal motions were used. They were evaluated with special interest to the tROM C2-5 as the sum of the neutral and elastic zones ( $\mathrm{ROM}=$ $\mathrm{NZ}+\mathrm{EZ}$ ) and representing the peak tROM (Euler angles' rotation). The NZ is the displacement between the neutral position and the initiation point of spinal resistance to physiological motion and was calculated as well. Analogous to the tROM, the iROM at the three segments $\mathrm{C} 2 / 3, \mathrm{C} 3 / 4$ and $\mathrm{C} 4 / 5$ was quantified in terms of peak ROM at maximum load. The values were compared among the three different spine conditions and the percent changes in case of simulated fusion and TDR were correlated to the intact situation. The IDP in $\mathrm{C} 2 / 3$ and $\mathrm{C} 4 / 5$ in all three conditions was calculated directly to the motion angle corresponding to $90 \%$ of the value of the maximum motion angle in

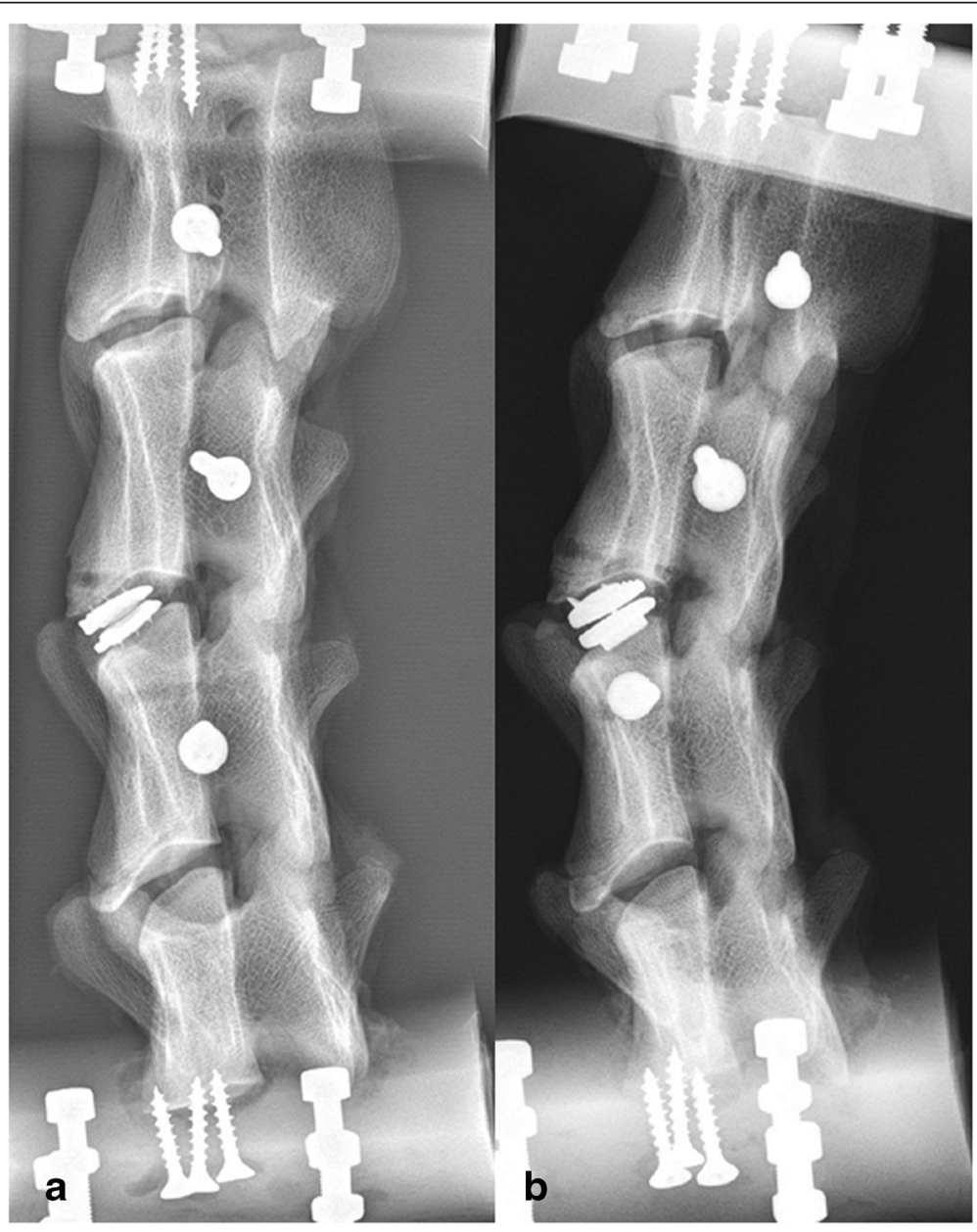

Figure 3 Lateral radiograph of two different specimens. Demonstration of the correct position of the Type D-prosthesis (a) and the Type A-prosthesis (b). 
the fused specimen. Differences between the TDR and the other conditions (intact, arthrodesis), were compared using a paired Student's t-test, differences between both types of the prosthesis using an unpaired Student's t-test. A significance level of $\mathrm{p}<0.05$ was applied.

\section{Results}

\section{Total ROM}

The differences between the two groups in the intact condition were not statistically significant in all three motion directions with the following values: for flexionextension $35.38^{\circ} \pm 6.57$ (group 1) versus $34.82^{\circ} \pm 3.64$ (group 2), for lateral bending $66.02^{\circ} \pm 9.96$ (group 1) versus $67.48^{\circ} \pm 9.51$ (group 2), and for axial rotation $16.75^{\circ} \pm 4.77$ (group 1) versus $15.25^{\circ} \pm 5.05$ (group 2). The mean tROM in flexion-extension, lateral bending and axial rotation was always recorded at the maximum loading of $\pm 2 \mathrm{Nm}$ (Figure 4a, b). In both specimen groups (group 1 and 2) we found significant different changes in flexion-extension between these conditions: intact to arthrodesis (decrease, $\mathrm{p}=0.000$ group $1 ; \mathrm{p}=0.047$ group 2 ), arthrodesis to TDR (increase, $\mathrm{p}=0.001$ group 1 ; $\mathrm{p}=0.023$ group 2) and intact to TDR (increase, $\mathrm{p}=0.005$ group $1 ; \mathrm{p}=0.042$ group 2). In lateral bending, only in the first six cadavers (group 1 ) was the difference significant between these both situations: intact to fusion (decrease, $\mathrm{p}=0.001$ ) and arthrodesis to TDR Type D (increase, $\mathrm{p}=0.003$ ). Also, in axial rotation, significant increases were seen only in the TDR Type D-group between the intact and the prosthetic condition $(\mathrm{p}=0.017)$ as well as between the state of fusion and TDR $(\mathrm{p}=0.011)$.

When both types of prosthesis were directly compared with each other, we found no significant differences in tROM for flexion-extension $(\mathrm{p}=0.598)$, lateral bending $(\mathrm{p}=0.652)$, or in axial rotation $(\mathrm{p}=0.322)$.

The percentual changes of the fused condition and the state with TDR in relation to the intact situation showed in all three motion directions almost always decreasing after arthrodesis and increasing after arthroplasty in both groups (Table 1). In flexionextension, tROM decreased by $26.68 \%$ in group 1 and by $14.19 \%$ in group 2 . In lateral bending, we observed similar values with decreasing by $22.06 \%$ in group 1 and by $13.95 \%$ in group 2. In axial rotation, the changes were low with decreasing by $1.62 \%$ in group 1 and increasing by $3.08 \%$ in group 2. After implantation of the Type D-prosthesis, tROM increased by $30.77 \%$ in flexion-extension, by $9.84 \%$ in lateral

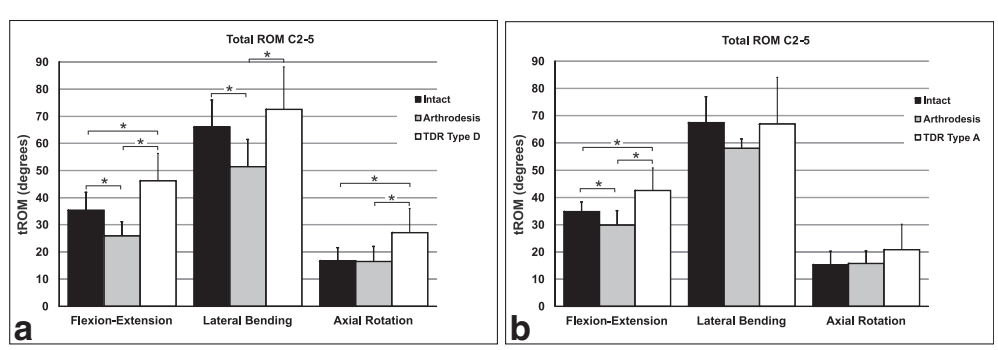

Figure 4 Mean tROM [degrees] with standard deviation at the maximum loading of $\pm 2 \mathrm{Nm}$. Range of motion in flexion-extension, lateral bending and axial rotation in the three different conditions: intact, arthrodesis C3/4 and TDR C3/4 with Type D-prosthesis (a) and Type A-prosthesis (b). Statistically significant differences are signed by * with bars connecting the corresponding columns. 
Table 1 Changes [\%] of tROM of the fused condition and the state with TDR in relation to the intact situation

\begin{tabular}{|c|c|c|c|c|c|c|}
\hline \multirow[t]{2}{*}{ tROM C2-5 } & \multicolumn{3}{|c|}{ Arthrodesis (group 1) } & \multicolumn{3}{|l|}{ TDR Type D } \\
\hline & Flexion-extension & $\begin{array}{l}\text { Lateral } \\
\text { bending }\end{array}$ & $\begin{array}{l}\text { Axial } \\
\text { rotation }\end{array}$ & Flexion-extension & $\begin{array}{l}\text { Lateral } \\
\text { bending }\end{array}$ & $\begin{array}{l}\text { Axial } \\
\text { rotation }\end{array}$ \\
\hline Mean & -26.68 & -22.06 & -1.62 & 30.77 & 9.84 & 61.96 \\
\hline SD & 6.20 & 7.93 & 23.76 & 16.15 & 14.35 & 43.11 \\
\hline \multirow[t]{2}{*}{ tROM C2-5 } & \multicolumn{3}{|c|}{ Arthrodesis (group 2) } & \multicolumn{3}{|l|}{ TDR Type A } \\
\hline & Flexion-extension & $\begin{array}{l}\text { Lateral } \\
\text { bending }\end{array}$ & $\begin{array}{l}\text { Axial } \\
\text { rotation }\end{array}$ & Flexion-extension & $\begin{array}{l}\text { Lateral } \\
\text { bending }\end{array}$ & $\begin{array}{l}\text { Axial } \\
\text { rotation }\end{array}$ \\
\hline Mean & -14.19 & -13.95 & 3.08 & 22.05 & -0.65 & 36.67 \\
\hline SD & 13.26 & 14.03 & 20.74 & 19.93 & 15.07 & 35.44 \\
\hline
\end{tabular}

SD means standard deviation.

bending, and by $61.96 \%$ in axial rotation, in relation to the intact condition. In the TDR Type A-group, we also observed an increasing by $22.05 \%$ in flexion-extension and by $36.67 \%$ in axial rotation, whereas in lateral bending there was a slight decreasing by $0.65 \%$.

\section{Intervertebral ROM}

The mean absolute values of the iROM C2/3, C3/4 and C4/5 in the intact condition increased from cranial to caudal in flexion-extension in both cadaver groups $\left(\mathrm{C} 2 / 3: 8.22^{\circ}\right.$ and $9.52^{\circ}$ in group 1 and group 2, C3/4: $11.74^{\circ}$ and $11.54^{\circ}$ in group 1 and group 2, C4/5: $14.89^{\circ}$ and $13.55^{\circ}$ in group 1 and group 2) (Table 2). In lateral bending, we found the following distribution in the intact state: $\mathrm{C} 2 / 3: 21.38^{\circ}$ (group 1) and $21.36^{\circ}$ (group 2), C3/4: $20.89^{\circ}$ (group 1 ) and $21.16^{\circ}$ (group 2), C4/5: $23.57^{\circ}$ (group 1 ) and $22.89^{\circ}$ (group 2). In axial rotation, the corresponding values were in $\mathrm{C} 2 / 35.52^{\circ}$ and $8.11^{\circ}$ in group 1 and group 2 , in $\mathrm{C} 3 / 45.44^{\circ}$ and $7.46^{\circ}$ in group 1 and group 2, and in $\mathrm{C} 4 / 5: 7.69^{\circ}$ and $6.48^{\circ}$ in group 1 and group 2.

The percentual changes of the fused condition and the state with TDR in relation to the intact situation showed significant differences in group 1 in flexion-extension $\mathrm{iROM}$ between arthrodesis and intact in C3/4 (decrease by $86.18 \%, \mathrm{p}=0.001$ ) and $\mathrm{C} 4 / 5$ (increase by $6.66 \%, \mathrm{p}=0.024$ ), between Type $\mathrm{D}$-prosthesis and intact in $\mathrm{C} 2 / 3$ (increase by $13.93 \%, \mathrm{p}=0.037$ ), $\mathrm{C} 3 / 4$ (increase by $64.58 \%, \mathrm{p}=0.007$ ), and $\mathrm{C} 4 / 5$ (increase by $11.65 \%$, $\mathrm{p}=0.009$ ) (Table 2). The increased iROM between TDR and fusion was significant in all three levels $(\mathrm{p}=0.038$ in $\mathrm{C} 2 / 3, \mathrm{p}=0.001$ in $\mathrm{C} 3 / 4, \mathrm{p}=0.044$ in $\mathrm{C} 4 / 5)$. A significant decrease of lateral bending iROM by $77.15 \%$ was observed in the fused situation in C3/4 $(\mathrm{p}=0.000)$, and a significant increase was seen between TDR and arthrodesis in the same segment $(\mathrm{p}=0.002)$. In axial rotation, a significant increase of iROM in C4/5 had occurred only after arthroplasty by $72.31 \%$ in comparison to the intact $(\mathrm{p}=0.012)$ and fused state $(\mathrm{p}=0.032)$.

In comparison to the TDR Type D-group, less variations appeared in the TDR Type A-group with significant differences however observed in flexion-extension iROM between arthrodesis and intact in $\mathrm{C} 2 / 3$ (increase by $11.85 \%, \mathrm{p}=0.007$ ), in C3/4 (decrease by $62.01 \%, \mathrm{p}=0.009$ ), and in $\mathrm{C} 4 / 5$ (increase by $8.92 \%, \mathrm{p}=0.002$ ). After arthroplasty, a significant increase in iROM was seen in $\mathrm{C} 2 / 3$ by $14.29 \%,(\mathrm{p}=0.011)$ and $\mathrm{C} 4 / 5$ by $10.75 \%(\mathrm{p}=0.032)$ compared to the intact cadavers. In $\mathrm{C} 3 / 4$, a significant increase was 
Table 2 Values of the mean iROM [degrees] C2/3, C3/4 and C4/5 in both cadaver groups in flexion-extension, lateral bending, and axial rotation and changes [\%] of the fused condition and the state with TDR in relation to the intact situation

\begin{tabular}{|c|c|c|c|c|c|c|c|c|c|}
\hline \multirow{2}{*}{$\begin{array}{l}\text { iROM, F/E } \\
\text { Group } 1\end{array}$} & \multicolumn{3}{|l|}{ Intact } & \multicolumn{3}{|c|}{ Arthrodesis } & \multicolumn{3}{|c|}{ TDR Type D } \\
\hline & $\mathrm{C} 2 / 3$ & C3/4 & $\mathrm{C} 4 / 5$ & $\mathrm{C} 2 / 3$ & $\mathrm{C} 3 / 4$ & $\mathrm{C} 4 / 5$ & $\mathrm{C} 2 / 3$ & $\mathrm{C} 3 / 4$ & C4/5 \\
\hline Mean & 8.22 & 11.74 & 14.89 & 8.64 & $1.62^{*}$ & $15.88^{*}$ & $9.37^{* \#}$ & $19.31^{* \#}$ & $16.63^{*} \#$ \\
\hline SD & 2.48 & 1.85 & 2.35 & 2.92 & 1.20 & 2.90 & 3.09 & 4.68 & 2.95 \\
\hline Change [\%] & & & & 5.06 & -86.18 & 6.66 & 13.93 & 64.58 & 11.65 \\
\hline iROM, LB & \multicolumn{3}{|l|}{ Intact } & \multicolumn{3}{|c|}{ Arthrodesis } & \multicolumn{3}{|c|}{ TDR Type D } \\
\hline Group 1 & $\mathrm{C} 2 / 3$ & $\mathrm{C} 3 / 4$ & $\mathrm{C} 4 / 5$ & $\mathrm{C} 2 / 3$ & $\mathrm{C} 3 / 4$ & $\mathrm{C} 4 / 5$ & $\mathrm{C} 2 / 3$ & $\mathrm{C} 3 / 4$ & $\mathrm{C} 4 / 5$ \\
\hline Mean & 21.38 & 20.89 & 23.57 & 21.55 & $4.77^{*}$ & 23.94 & 22.84 & 21.72\# & 22.84 \\
\hline SD & 4.82 & 2.52 & 3.00 & 4.39 & 2.93 & 3.36 & 4.14 & 6.85 & 3.99 \\
\hline Change [\%] & & & & 0.80 & -77.15 & 1.57 & 6.84 & 3.97 & -3.10 \\
\hline iROM, AR & \multicolumn{3}{|l|}{ Intact } & \multicolumn{3}{|c|}{ Arthrodesis } & \multicolumn{3}{|c|}{ TDR Type D } \\
\hline Group 1 & $\mathrm{C} 2 / 3$ & $\mathrm{C} 3 / 4$ & $\mathrm{C} 4 / 5$ & $\mathrm{C} 2 / 3$ & $\mathrm{C} 3 / 4$ & $\mathrm{C} 4 / 5$ & $\mathrm{C} 2 / 3$ & $\mathrm{C} 3 / 4$ & $\mathrm{C} 4 / 5$ \\
\hline Mean & 5.52 & 5.44 & 7.69 & 6.36 & 4.59 & 8.52 & 6.31 & 10.93 & $13.26^{*} \#$ \\
\hline SD & 2.20 & 1.73 & 3.70 & 2.35 & 2.60 & 3.13 & 2.44 & 4.37 & 2.83 \\
\hline Change [\%] & & & & 15.27 & -15.50 & 10.77 & 14.32 & 100.95 & 72.31 \\
\hline iROM, F/E & \multicolumn{3}{|l|}{ Intact } & \multicolumn{3}{|c|}{ Arthrodesis } & \multicolumn{3}{|c|}{ TDR Type A } \\
\hline Group 2 & $\overline{C 2 / 3}$ & $\mathrm{C} 3 / 4$ & $\mathrm{C} 4 / 5$ & $\mathrm{C} 2 / 3$ & $\mathrm{C} 3 / 4$ & $\mathrm{C} 4 / 5$ & $\mathrm{C} 2 / 3$ & $\mathrm{C} 3 / 4$ & C4/5 \\
\hline Mean & 9.52 & 11.54 & 13.55 & $10.65^{*}$ & $4.38^{*}$ & $14.76^{*}$ & $10.88^{*}$ & 16.01\# & $15.01^{*}$ \\
\hline SD & 3.33 & 1.31 & 1.60 & 3.68 & 2.92 & 1.70 & 3.74 & 5.35 & 1.52 \\
\hline Change [\%] & & & & 11.85 & -62.01 & 8.92 & 14.29 & 38.69 & 10.75 \\
\hline iROM, LB & \multicolumn{3}{|l|}{ Intact } & \multicolumn{3}{|c|}{ Arthrodesis } & \multicolumn{3}{|c|}{ TDR Type A } \\
\hline Group 2 & $\mathrm{C} 2 / 3$ & $\mathrm{C} 3 / 4$ & $\mathrm{C} 4 / 5$ & $\mathrm{C} 2 / 3$ & $\mathrm{C} 3 / 4$ & $\mathrm{C} 4 / 5$ & $\mathrm{C} 2 / 3$ & $\mathrm{C} 3 / 4$ & $\mathrm{C} 4 / 5$ \\
\hline Mean & 21.36 & 21.16 & 22.89 & 22.22 & $10.11^{*}$ & 23.87 & 22.89 & 21.00 & 23.53 \\
\hline SD & 2.69 & 3.56 & 1.80 & 4.17 & 3.50 & 1.60 & 4.23 & 13.38 & 2.96 \\
\hline Change [\%] & & & & 4.05 & -52.23 & 4.28 & 7.17 & -0.77 & 2.83 \\
\hline iROM, AR & \multicolumn{3}{|l|}{ Intact } & \multicolumn{3}{|c|}{ Arthrodesis } & \multicolumn{3}{|c|}{ TDR Type A } \\
\hline Group 2 & $\mathrm{C} 2 / 3$ & $\mathrm{C} 3 / 4$ & $\mathrm{C} 4 / 5$ & $\mathrm{C} 2 / 3$ & $\mathrm{C} 3 / 4$ & $\mathrm{C} 4 / 5$ & $\mathrm{C} 2 / 3$ & $\mathrm{C} 3 / 4$ & $\mathrm{C} 4 / 5$ \\
\hline Mean & 8.11 & 7.46 & 6.48 & 6.37 & 4.45 & $7.06^{*}$ & 5.98 & 9.72 & 10.71 \\
\hline SD & 5.12 & 3.12 & 2.45 & 2.40 & 1.55 & 2.01 & 2.32 & 5.30 & 3.94 \\
\hline Change [\%] & & & & -21.44 & -40.31 & 9.03 & -26.20 & 30.26 & 65.37 \\
\hline
\end{tabular}

detected in relation to arthrodesis $(\mathrm{p}=0.028)$. In lateral bending, the only significant change was seen in $\mathrm{C} 3 / 4$ after fusion (decrease by $52.23 \%, \mathrm{p}=0.016$ ) and in axial rotation the only significant difference was after arthrodesis in C4/5 (increase by $9.03 \%$, $\mathrm{p}=0.027$ ), always in correlation to intact.

When comparing both types of prosthesis directly, we found no significant differences in iROM of $\mathrm{C} 2 / 3$ ( $\mathrm{p}=0.616$ in flexion-extension, $\mathrm{p}=0.989$ in lateral bending, $\mathrm{p}=0.875$ in axial rotation), $\mathrm{C} 3 / 4(\mathrm{p}=0.381$ in flexion-extension, $\mathrm{p}=0.919$ in lateral bending, $\mathrm{p}=0.753$ in axial rotation) or $\mathrm{C} 4 / 5$ ( $\mathrm{p}=0.412$ in flexion-extension, $\mathrm{p}=0.786$ in lateral bending, $\mathrm{p}=0.369$ in axial rotation).

In addition to the absolute values, we analyzed the relative distribution of the iROM with respect to tROM for each motion segment $\mathrm{C} 2 / 3, \mathrm{C} 3 / 4$, and $\mathrm{C} 4 / 5$ (Figure $5 \mathrm{a}-\mathrm{f}$ ). In 


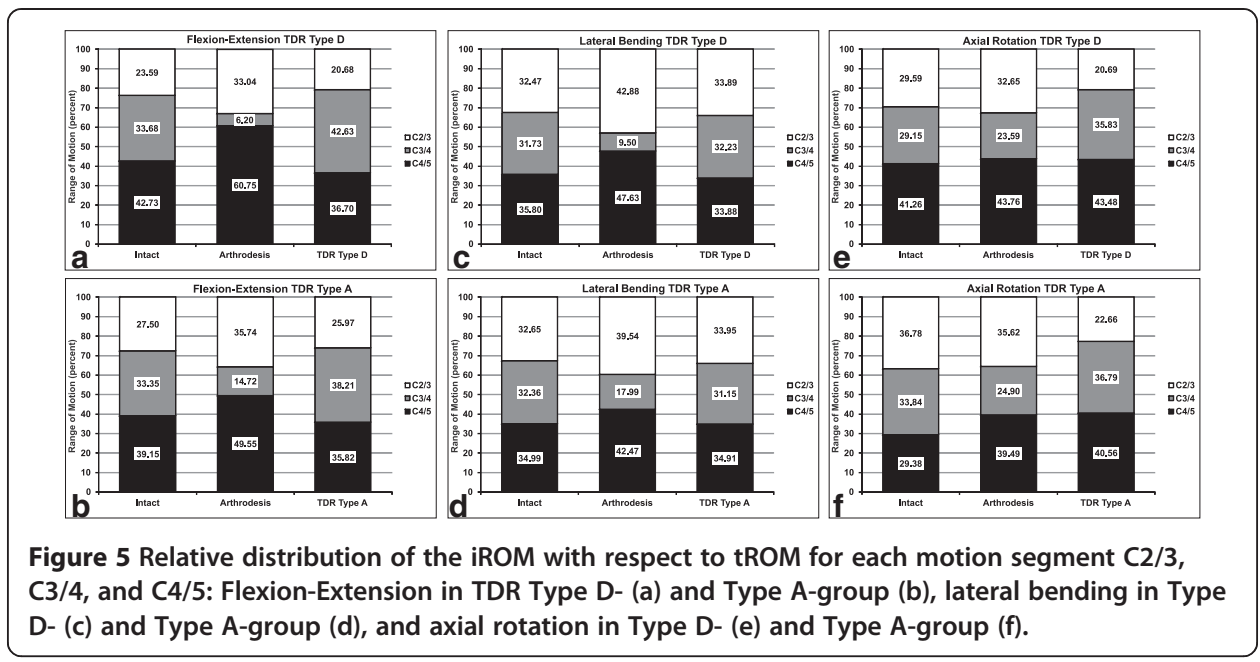

flexion-extension, the relative iROM decreased in the treated segment after arthrodesis in both groups (from $33.68 \%$ to $6.20 \%$ in group 1, from $33.35 \%$ to $14.72 \%$ in group 2) (Figure $5 \mathrm{a}, \mathrm{b}$ ). In the neighboring levels, the relative iROM always increased (in $\mathrm{C} 2 / 3$ from $23.59 \%$ to $33.04 \%$ in group 1 and from $27.50 \%$ to $35.74 \%$ in group 2, and in C4/5 from $42.73 \%$ to $60.75 \%$ in group 1 and from $39.15 \%$ to $49.55 \%$ in group 2). After implantation of both types of disc prosthesis, the relative iROM in the aim segment showed increasing with higher values compared to the intact situation (from $33.68 \%$ to $42.63 \%$ in TDR Type D-group, from $33.35 \%$ to $38.21 \%$ in TDR Type A-group). In contrast, we observed lower relative iROM in the adjacent levels compared to the physiologic state (in $\mathrm{C} 2 / 3$ from $23.59 \%$ to $20.68 \%$ in group 1 and from $27.50 \%$ to $25.97 \%$ in group 2, and in C4/5 from $42.73 \%$ to $36.70 \%$ in group 1 and from $39.15 \%$ to $35.82 \%$ in group 2). In the other two motion directions, we observed the same trend in the aim segment with decreasing of relative iROM after arthrodesis from $31.73 \%$ to $9.50 \%$ (lateral bending in group 1) and from $32.36 \%$ to $17.99 \%$ (lateral bending in group 2), as well as for axial rotation from $29.15 \%$ to $23.59 \%$ in group 1 and from $33.84 \%$ to $24.90 \%$ in group 2 (Figure $5 \mathrm{c}, \mathrm{d}, \mathrm{e}, \mathrm{f}$ ). In both neighboring levels, the relative iROM always increased after fusion, except for slight decrease in $\mathrm{C} 2 / 3$ in axial rotation in group 2 (from $36.78 \%$ to $35.62 \%$ ). After arthroplasty, the relative iROM in the target segment showed always increasing in lateral bending and axial rotation compared to intact, except for slight decreasing in lateral bending from $32.36 \%$ to $31.15 \%$ in the TDR Type A-group. In each of the adjacent levels, there was no uniform pattern with some increasing and some decreasing relative values in lateral bending and axial rotation.

\section{Intradiscal pressure analysis}

The IDP always showed higher values in flexion and extension in the level above and below the fused segment, compared to the intact condition, which was expressed as percentual changes (Figure 6a, b). In flexion, the increasing of the IDP was always statistically significant in both discs (in $\mathrm{C} 2 / 3$ increase by $172.05 \%$ in group $1, \mathrm{p}=0.004$ and by $59.05 \%$ in group $2, \mathrm{p}=0.043$, in $\mathrm{C} 4 / 5$ by $324.26 \%$ in group $1, \mathrm{p}=0.000$ and by $65.49 \%$ in group $2, \mathrm{p}=0.016$ ). In extension, the IDP had also increased in the adjacent discs (in $\mathrm{C} 2 / 3$ by $41.47 \%$ in group 1 and by $81.11 \%$ in group 2, in C4/5 by $51.77 \%$ in 


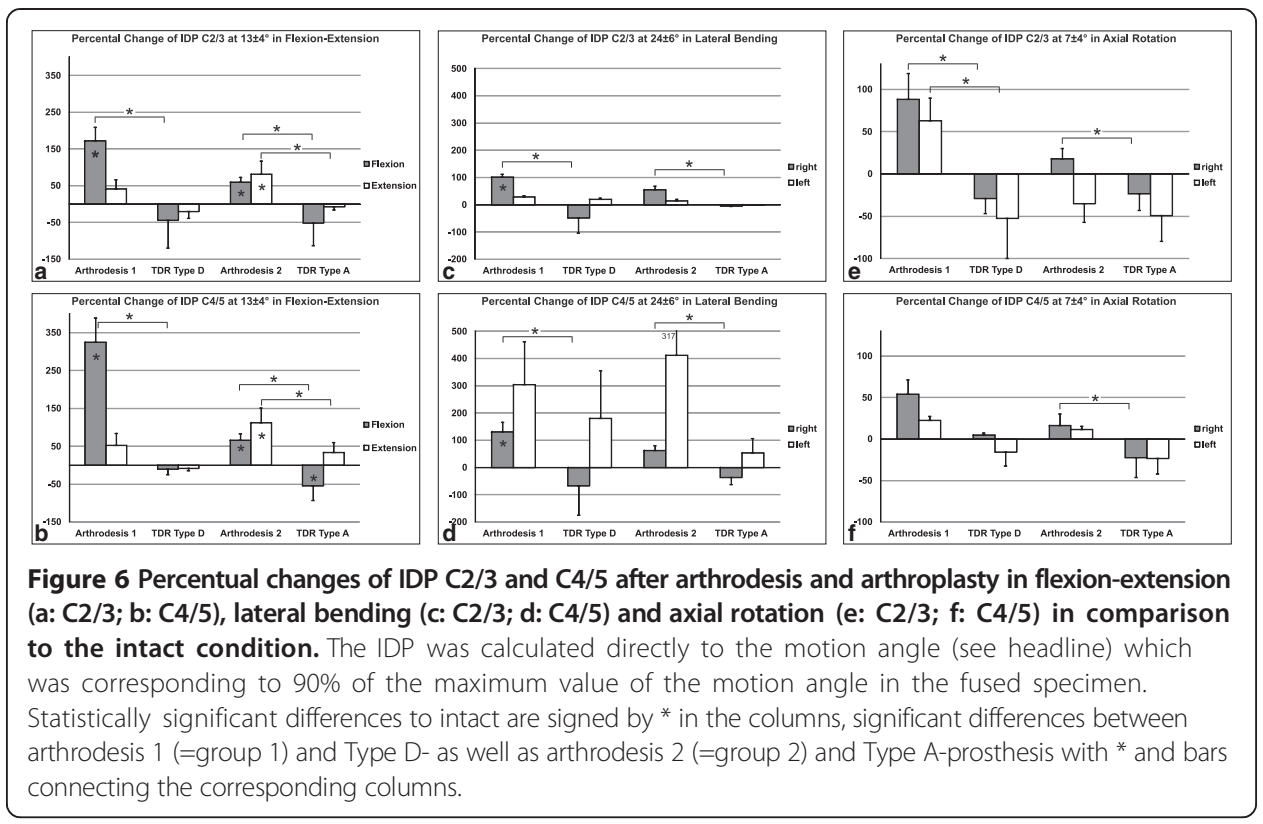

group 1 and by $112.12 \%$ in group 2), but statistically significant only in group 2 (in C2/3 $\mathrm{p}=0.004$, in $\mathrm{C} 4 / 5 \mathrm{p}=0.008$ ). After arthroplasty, we always observed decreased IDP below the values of the intact condition in flexion in the cranial and caudal level (in $\mathrm{C} 2 / 3$ decrease by $44.30 \%$ with TDR Type D and by $51.79 \%$ with TDR Type A, in C4/5 by $10.85 \%$ with TDR Type D and by $54.50 \%$ with TDR Type A, $\mathrm{p}=0.040$ ). In extension, TDR led also to decreased IDP in the neighboring segments, except for C4/5 in the TDR Type A-group (increase by $33.12 \%$ ).

In lateral bending, we always observed increase of IDP in C2/3 and C4/5 after arthrodesis with statistical significance in both segments to the right side in group 1 (in $\mathrm{C} 2 / 3$ increase by $101.90 \%, \mathrm{p}=0.003$, in $\mathrm{C} 4 / 5$ by $130.15 \%, \mathrm{p}=0.001$ ) (Figure $6 \mathrm{c}$, d). After TDR, the changes were not significantly different compared to the intact situation, and increasing (mostly to the left side of direction) as well as decreasing (always to the right side) of the IDP had occurred.

In axial rotation, the IDP showed increased values after fusion in comparison to the physiologic state except for the motion direction to the left side in C2/3 in group 2 (decrease by $35.22 \%$ ) (Figure 6e, f). All changes were not significantly different. With arthroplasty, we mostly observed decreased IDP in both groups to both directions except for a slight increase (by 4.75\%) to the right side in the TDR Type D-group in C4/5. Again, the changes were not significantly different.

When comparing both types of TDR directly, we found no significant differences in the changes between the Type D- and Type A-prosthesis regarding the IDP in $\mathrm{C} 2 / 3$ ( $\mathrm{p}=0.854$ in flexion, $\mathrm{p}=0.958$ in extension, $\mathrm{p}=0.186$ in lateral bending to the right side, $\mathrm{p}=0.103$ in lateral bending to the left side, $\mathrm{p}=0.770$ in axial rotation to the right side, $\mathrm{p}=0.898$ in axial rotation to the left side) and in $\mathrm{C} 4 / 5(\mathrm{p}=0.803$ in flexion, $\mathrm{p}=0.943$ in extension, $\mathrm{p}=0.219$ in lateral bending to the right side, $\mathrm{p}=0.148$ in lateral bending to the left side, $\mathrm{p}=0.312$ in axial rotation to the right side, $\mathrm{p}=0.939$ in axial rotation to the left side). 


\section{Discussion}

As motion preservation technology is of great interest in the operative management of degenerative disc disease in the lumbar as well as in the cervical spine, in vitro-studies are important to investigate the biomechanical behavior of the different implants. In our study we tested the kinematics of polysegmental cervical cadavers from sheep under three different conditions (intact, arthrodesis and two types of semi-constrained arthroplasty). Furthermore, the pressures in the discs adjacent to the aim segment were analyzed.

As expected, total range of motion (tROM) of $\mathrm{C} 2-5$ decreased after simulating arthrodesis in the target segment $\mathrm{C} 3 / 4$ whereas this finding was almost without exception the clearest in the flexion-extension direction. After arthroplasty, we consistently observed an increasing tROM C2-5 in the three directions tested when compared to the intact condition, the increase was even more pronounced when contrasted to the fused situation. When comparing the data of both types of semi-constrained prosthesis, we always observed higher values of tROM with the TDR Type D than with the Type Adevice. This suggests, that the Type A-prosthesis has some characteristics in its design which allow it to more closely approach the physiologic kinematic situation in the cervical spine. None the less, the differences between each of the prosthesis never reached statistical significance.

We further found increasing values of segmental ROM in the intact specimens, when progressing from the cranial to the caudal level in flexion-extension, and this progression was more distinct than in lateral bending and axial rotation. After fusion of C3/4, expectedly, the ROM in this segment always significantly decreased in flexionextension and lateral bending in both groups. With each type of TDR, we almost always observed higher values compared to the intact state in C3/4, and with the Type D-prosthesis the relative changes were always more pronounced than with the TDR Type A. In direct comparison, the differences between both prosthesis were not statistically significant. Concerning the adjacent levels, we get the best information when analyzing the percentual distribution of the $\mathrm{iROM}$ in relation to the tROM, because it is independent of the absolute values of the tROM. In the intact state, we see a relative equal fraction of the percentual iROM of the three levels. After arthrodesis, the percentual iROM in the target segment C3/4 was always lowered after fusion in the three directions of motion with most reduction in flexion-extension and lateral bending in group 1 and least decreased in axial rotation in both specimen groups. Consecutively, the motion was clearly spread to each of the neighboring motion segment, most impressive in flexion-extension and lateral bending indicating a certain overload. Therefore, the percentual iROM of the neighboring levels was almost always higher $(\mathrm{C} 2 / 3$ more than C4/5) compared to the intact condition. After arthroplasty, we found always increased percentual iROM in the target level in comparison to intact state (except for lateral bending in TDR Type A-group) with percentual iROM in the adjacent segments even below the initial values, except for $\mathrm{C} 2 / 3$ in lateral bending and for $\mathrm{C} 4 / 5$ in axial rotation in both groups. These findings suggest that, from a biomechanical point of view, both semi-constrained prosthesis have influence on the target and adjacent level with leading to a certain hypermobility in the aim segments and lowering the ROM in the adjacent levels in most situations.

When we discuss our results of the IDP, we have to consider, that we did not analyze the peak values but the data which were calculated directly to the motion angle 
corresponding to $90 \%$ of the value of the maximum motion angle in the fused specimen. This technique became necessary because sometimes the maximum values of the IDP could not be recorded by the transducers due to extreme range of motion angles which led to pressures beyond the measuring zone, especially in the fused state. Therefore, we did not show absolute data but percentual changes of the pressure, which permits an appropriate interpretation of the results. The findings of the IDP were similar to those of the iROM in the neighboring segments. After fusion, the percentual change of the IDP was significantly higher in $\mathrm{C} 2 / 3$ and $\mathrm{C} 4 / 5$ in both specimen groups in flexion, but in extension only in the group 1, compared to the intact condition. After arthroplasty, the IDP showed decreasing in each adjacent level in flexion and extension except for extension in C4/5 with the Type A-prosthesis. In lateral bending (to the right and left side), the IDP was constantly higher in both adjacent disc spaces after simulated arthrodesis. After TDR, the IDP was lowered in $\mathrm{C} 2 / 3$ and $\mathrm{C} 4 / 5$ in lateral bending to the right side, but not significantly increased to the left side. In axial rotation and after fusion, we always observed not significantly increased IDP in C2/3 and C4/5 except for the left side in group 1 . After arthroplasty, the IDP was always not significantly decreased below the initial values in both segments. We only found a not significant slight increase in C4/5 in the TDR Type D-group in axial rotation to the right side.

In summary, none of the analyzed parameters (tROM, iROM, IDP) showed any statistically significant differences between both types of prosthesis, even though the Type A-prosthesis demonstrated a more similar kinematic behavior to the intact condition than the Type D-TDR, which could eventually be an evidence of a certain degree of hypermobility of the Type D-prosthesis.

If we compare our own results with the data from other investigations, we have to consider the different study designs, which had been utilized. However, the optimal testing method has not been validated yet, so that a standardized testing protocol for analogous experiments is not available yet [22]. Nevertheless, a trend can definitely be recognized. In several experimental studies, the iROM in levels adjacent to a simulated fusion was shown to increase [5-11,13,23-25]. After TDR, the iROM in the neighboring segments approximated the corresponding values of the intact condition [5,6,8,14,23-26]. There are only two published in vitro-studies which investigated the kinematics after implantation of the Discover-prosthesis in a comparable test set-up to our model [25,26]. In the presented study and the evaluation of Phillips et al., the relative changes in the target segment showed significantly increasing of iROM in flexion-extension (64.6\% and 43.0\%) and not significantly increasing of iROM in axial rotation (101.0\% and $9.1 \%)$, whereas in lateral bending we found no significant differences ( $4.0 \%$ and $-18.9 \%)$, always compared to the intact condition [26]. Terai et al. recorded only in extension a $22 \%$ decrease of iROM in the treated motion segment (not significant) [25]. In flexion, lateral bending and axial rotation the changes in the iROM were similar or lower than to the intact state. Both authors did not report any significant differences of the percentual changes in the neighboring levels after implantation of the Discover-prosthesis $[25,26]$. This is in contrast to our study, because in flexion-extension we found a significant higher iROM in both adjacent segments, compared to the intact cadavers, as well as in the caudal adjacent level in axial rotation. No kinematic data about the activ ${ }^{\circ} \mathrm{C}$-prosthesis have been published to date. The analyses of the IDP in the present study show the same trend seen in comparable investigations with increases in the levels above and below a simulated arthrodesis 
$[8,9,11,12]$. After TDR, the values of the IDP in the adjacent segments approximate to the values of the intact situation $[4,8]$.

Finally, the animal model and the experimental set-up are to be discussed. As already mentioned, the optimal testing method has probably not been found to date which is the conclusion of a critical review of concurrent biomechanical testing systems [22]. Probably for this reason, several different techniques to perform such experimental implant testing have been applied. Most studies utilize human cadaveric specimens, because the implants of interest are designed for clinical use in the human spine. However, we know that there are some disadvantages to human tissue testing, for instance the variability in age, height, gender, stiffness, bone quality, and grade of degenerative changes. If the goal is to perform a comparative analysis of modern motion preservation technology like TDR, it is essential to have specimens without relevant degeneration and which are of readily availability. Therefore, as others have suggested, we used the cervical spine from sheep as an accepted substitute for the human cervical spine [16-18]. When comparing our own results in the twelve ovine spines in the physiologic condition, we found a very good reproducibility of the kinematics to similar animal and human experiments. According to the study of Kandziora et al., we chose the C3/4 segment as the target level for implant testing [16]. The robot used in the present study is a validated method against the Pure Moment Apparatus (PMA) and capable of applying pure, unconstrained rotational moments about three axes $(x, y, z)$ [19]. Therewith, it meets all the demands of a spine tester, according to the recommendations of Wilke et al. [27]. One limitation of all PMA techniques is that the reference position of the specimen is force-free since it lies within the NZ of the polysegmental specimen, and is thus difficult to define. This may in part explain the asymmetrical behavior of the IDP in lateral bending and axial rotation with respect to the right versus the left side. Another declarative aspect is the fact, that we know from previous biomechanical studies with calf spines, that they behave asymmetrically [28-30]. Another possible reason for the not symmetrical distribution of the IDP to both directions in lateral bending and axial rotation can be the position of the pressure measuring sensors. Although all these transducers had been controlled by fluoroscopy in a.p. and lateral view after insertion into the disc to verify a central position in the nucleus pulposus, it cannot totally be excluded that some movement of the measuring sensors had occurred during the testing cycles even if the pressure data were recorded under continuous visual control on a display. Therefore the findings of the IDP especially in lateral bending and axial rotation should be interpreted with caution and are not be overestimated. Some investigators performed similar experimental testing with additional preload application to the specimens to imitate the influence of muscle strength $[4-6,12,15,26]$ in contrast to the presented study, which was performed without any preload or muscle simulation analogous to previous evaluations $[8,9,13,24,25]$. Therefore, we showed the values for ROM and IDP not only as absolute data but also as relative changes in percentage which are expected to demonstrate the same tendency with or without any load application. However, under the influence of muscle simulation or with the use of a preload the absolute values of ROM should be decreased whereas the absolute values of IDP should be increased which is known from literature [31-33]. The applied loads in form of a pure moment with $\pm 2.0 \mathrm{Nm}$ and without an axial preload are in the lower range for an in vitro testing set-up for cervical spines. No damage of the bony structure or tissue was observed after testing. Therefore the range of motion of the in vitro tested ovine spines should be 
in the physiological range. As we do not know any values of the ovine spine for physical loads or for IDP in vitro and in vivo as well as for ROM in vivo only the relative changes in IDP after simulated fusion and arthroplasty compared to the intact state were presented and not the absolute values.

\title{
Conclusion
}

The results of both the presented biomechanical investigation and similar experimental studies indicate that single-level implantation of semi-constrained TDR lead to a certain hypermobility in the treated segments with lowering the ROM in the adjacent levels in almost all situations. Nevertheless, clinical long term follow-up studies over a period of 10 to 15 years remain indispensable to observe the course in vivo, i.e. in the patient itself in order to verify, if adjacent segment pathologies are to be avoided or postponed after TDR.

Competing interests

The authors declare that they have no competing interests.

\section{Authors' contributions}

The following authors have designed the study (DD, BW, CH, CHF, BIR), performed the experiments, gathered and analyzed the data (DD, BW, CH, NH, CJ, BIR), and ensured the accuracy of the data and analysis (DD, BW, CH, NH, CJ, BIR). All authors read and approved the final manuscript.

\section{Acknowledgements}

Financial support in the form of a research grant from Aesculap AG \& Co. KG, Tuttlingen, Germany and DePuySpine $\mathrm{GmbH}$, Kirkel-Limbach, Germany is gratefully acknowledged.

\begin{abstract}
Author details
${ }^{1}$ Orthopedic Department, Hannover Medical School, Diakoniekrankenhaus Annastift gGmbH, Anna-von-Borries-Str. 1-7, 30625 Hannover, Germany. 'Laboratory for Biomechanics and Biomaterials, Department of Orthopedics, Hannover Medical School, Anna-von-Borries-Str. 1-7, 30625 Hannover, Germany. '3 Department of Radiology, Asklepios Clinic Nord, Standort Heidberg, Tangstedter Landstr. 400, 22417 Hamburg, Germany. ${ }^{4}$ Department of Spine Surgery, Klinikum Bad Bramstedt GmbH, Oskar-Alexander-Str. 26, 24576 Bad Bramstedt, Germany. ${ }^{5}$ Clinic for Orthopedics and Traumatology, Asklepios Clinic Hamburg, Eißendorfer Pferdeweg 52, 21075 Hamburg, Germany. ${ }^{6}$ Aesculap AG, Am Aesculap-Platz, 78532 Tuttlingen, Germany.
\end{abstract}

Received: 11 July 2014 Accepted: 27 February 2015

Published online: 24 March 2015

\section{References}

1. Goffin J, Geusens E, Vantomme N, Quintens E, Waerzeggers Y, Depreitere B, et al. Long-term follow-up after interbody fusion of the cervical spine. J Spinal Disord Tech. 2004;17:79-85.

2. Gore DR, Sepic SB. Anterior discectomy and fusion for painful cervical disc disease: a report of 50 patients with an average follow-up of 21 years. Spine. 1998;23:2047-51.

3. Hilibrand AS, Carlson GD, Palumbo MA, Jones PK, Bohlman H. Radiculopathy and myelopathy at segments adjacent to the site of a previous anterior cervical arthrodesis. J Bone Joint Surg. 1999;81-A:519-28.

4. Chang U-K, Kim DH, Lee MC, Willenberg R, Kim S-H, Lim J. Changes in adjacent-level disc pressure and facet joint force after cervical arthroplasty compared with cervical discectomy and fusion. J Neurosurg Spine. 2007;7:33-9.

5. Chang U-K, Kim DH, Lee MC, Willenberg R, Kim S-H, Lim J. Range of motion change after cervical arthroplasty with ProDisc-C and Prestige artificial discs compared with anterior cervical discectomy and fusion. J Neurosurg Spine. 2007;7:40-6.

6. DiAngelo DJ, Foley KT, Morrow BR, Schwab JS, Song J, German JW, et al. In vitro biomechanics of cervical disc arthroplasty with the ProDisc-C total disc implant. Neurosurg Focus. 2004;17(E7):44-54.

7. DiAngelo DJ, Robertson JT, Metcalf NH, McVay BJ, Davis RC. Biomechanical testing of an artificial cervical joint and an anterior plate. J Spinal Disord Tech. 2003;16:314-23.

8. Dmitriev AE, Cunningham BW, Hu N, Sell G, Vigna F, McAfee PC. Adjacent level intradiscal pressure and segmental kinematics following a cervical total disc arthroplasty. An in vitro human cadaveric model. Spine. 2005;30:1165-72.

9. Eck JC, Humphreys SC, Lim T-H, Jeong ST, Kim JG, Hodges SD, et al. Biomechanical study on the effect of cervical spine fusion on adjacent-level intradiscal pressure and segmental motion. Spine. 2002;27:2431-4.

10. Fuller DA, Kirkpatrick JS, Emery SE. A kinematic study of the cervical spine before and after segmental arthrodesis. Spine. 1998;23:1649-56

11. Park D-H, Ramakrishnan P, Cho T-H, Lorenz E, Eck JC, Humphreys SC, et al. Effect of lower two-level anterior cervical fusion on the superior adjacent level. J Neurosurg Spine. 2007;7:336-40.

12. Pospiech J, Stolke D, Wilke HJ, Claes LE. Intradiscal pressure recordings in the cervical spine. Neurosurgery. 1999:44:379-84. 
13. Ragab AA, Escarcega AJ, Zdeblick TA. A quantitative analysis of strain at adjacent segments after segmental immobilization of the cervical spine. J Spinal Disord Tech. 2006;19:407-10.

14. Galbusera F, Bellini CM, Raimondi MT, Fornary M, Assietti R. Cervical spine biomechanics following implantation of a disc prosthesis. Med Eng Phys. 2008;30:1127-33.

15. Puttlitz CM, Rousseau MA, Xu Z, Hu S, Tay BK-B, Lotz JC. Intervertebral disc replacement maintains cervical spine kinetics. Spine. 2004;29:2809-14.

16. Kandziora F, Pflugmacher R, Scholz M, Schnake K, Lucke M, Schröder R, et al. Comparison between sheep and human cervical spines. An anatomic, radiographic, bone mineral density, and biomechanical study. Spine. 2001;26:1028-37.

17. Wilke HJ, Kettler A, Goetz C, Claes LE. Are sheep spines a valid biomechanical model for human spines? Spine. 2000;22:2762-70.

18. Wilke HJ, Kettler A, Wenger KH, Claes LE. Anatomy of the sheep spine and its comparison to the human spine. Anat Rec. 1997;247:542-55.

19. Hurschler C, Pott L, Gossé F, Wirth CJ. Sensor-guided robotic spine motion-segment biomechanical testing: validation against the pure moment apparatus. In Transactions of the 51st Annual Meeting of the Orthopedic Research Society; Vol. 30, Washington D.C.; 2005. Abstract

20. Schulte TL, Hurschler $C$, Haversath M, Liljenqvist U, Bullmann V, Filler TJ, et al. The effect of dynamic, semi-rigid implants on the range of motion of lumbar segments after decompression. Eur Spine J. 2008;17:1057-65.

21. McAfee PC, Cunningham B, Dmitriev A, Hu N, Kim SW, Cappucino A, et al. Cervical disc replacement - Porous coated motion prosthesis. A comparative biomechanical analysis showing the key role of the posterior longitudinal ligament. Spine. 2003;28:S176-85.

22. DiAngelo DJ, Foley KT. Biomechanical testing protocol for evaluating cervical disk arthroplasty. In: Kim DH Cammisa Jr FP, Fesler RG, editors. Dynamic reconstruction of the spine. New York: Stuttgart: Thieme; 2006. p. 33-41.

23. Cunningham BW, Hu N, Zorn CM, McAfee PC. Biomechanical comparison of single- and two-level cervical arthroplasty versus arthrodesis: effect on adjacent-level spinal kinematics. Spine J. 2010;10:341-9.

24. Kotani Y, Cunningham BW, Abumi K, Dmitriev AE, Ito M, Hu N, et al. Multidirectional flexibility analysis of cervical artificial disc reconstruction: in vitro human cadaveric spine model. J Neurosurg Spine. 2005;2:188-94.

25. Terai T, Faizan A, Sairyo K, Goel VK. Operated and adjacent segment motions for fusion versus cervical arthroplasty. A pilot study. Clin Orthop Relat Res. 2011;469:682-7.

26. Phillips FM, Tzermiadianos MN, Voronov LI, Havey RM, Carandang G, Dooris A, et al. Effect of two-level total disc replacement on cervical spine kinematics. Spine. 2009;34:E795-9.

27. Wilke $\mathrm{H}-J$, Wenger $\mathrm{K}$, Claes L. Testing criteria for spinal implants: recommendations for the standardization of in vitro stability testing of spinal implants. Eur Spine J. 1998;7:148-54.

28. Flamme $\mathrm{CH}$, Hurschler $\mathrm{C}$, Heymann $\mathrm{C}$, von der Heide N. Biomechanical testing of different ventral fixation devices on the bovine lumbar spine. Z Orthop. 2004;142:88-96.

29. Flamme CH, Hurschler C, Heymann C, von der Heide N. Comparative biomechanical testing of anterior and posterior stabilization procedures. Spine. 2005;30:E352-62.

30. Flamme $\mathrm{CH}$, von der Heide N, Heymann C, Hurschler C. Primary stability of anterior lumbar stabilization: interdependence of implant type and endplate retention or removal. Eur Spine J. 2006;15:807-18.

31. Patwardhan AG, Havey RM, Ghanayem AJ, Diener H, Meade KP, Dunlap B, et al. Load-carrying capacity of the human cervical spine in compression is increased under a follower load. Spine. 2000;25:1548-54.

32. Wilke $\mathrm{H}-J$, Wolf $\mathrm{S}$, Claes L, Arand $\mathrm{M}$, Wiesend A. Stability increase of the lumbar spine with different muscle groups: A biomechanical in vitro study. Spine. 1995;20:192-8.

33. Wilke $\mathrm{H}-J$, Wolf $\mathrm{S}$, Claes $\mathrm{L}$, Arand $\mathrm{M}$, Wiesend A. Influence of varying muscle forces on lumbar intradiscal pressure: an in vitro study. J Biomech. 1996;29:549-55.

\section{Submit your next manuscript to BioMed Central and take full advantage of:}

- Convenient online submission

- Thorough peer review

- No space constraints or color figure charges

- Immediate publication on acceptance

- Inclusion in PubMed, CAS, Scopus and Google Scholar

- Research which is freely available for redistribution

Submit your manuscript at www.biomedcentral.com/submit 